\title{
Acute myocardial infarction related to smoke inhalation and myocardial bridging
}

\author{
Michael J. McCabe*, Clive F.M. Weston and Alan G. Fraser \\ Department of Cardiology, University Hospital of Wales, Heath Park, Cardiff CF4 4XN, UK
}

\begin{abstract}
Summary: A previously healthy 26 year old woman who was exposed to smoke during a house fire developed acute anterior myocardial infarction complicated by ventricular fibrillation. Subsequent left ventriculography confirmed anterior infarction, but coronary arteriography was normal apart from myocardial bridging over-a segment of the left anterior descending artery. The development of acute myocardial infarction in this patient suggests that, in the presence of bridging, carbon monoxide inhalation may cause regional infarction.
\end{abstract}

\section{Introduction}

Acute carbon monoxide toxicity causes tissue hypoxia and evidence of diffuse myocardial damage. ${ }^{1}$ In patients with pre-existing coronary artery disease exposure to carbon monoxide may result in acute myocardial infarction. ${ }^{2}$ We report a case of acute myocardial infarction following smoke inhalation in which the only coronary artery abnormality was a segment of myocardial bridging. We postulate that such bridging is not always an innocent finding and played a part in the pathogenesis of this patient's myocardial infarction.

\section{Case report}

A previously healthy 26 year old woman, without significant coronary risk factors, was brought to the Accident and Emergency Department in a private car having been rescued from a house fire by her neighbours. On arrival at hospital she was in severe respiratory distress and immediately suffered a cardio-respiratory arrest. She was found to be in ventricular fibrillation and received a 200 joules shock before reverting to a sinus tachycardia. Initially she was deeply unconscious with reduced tendon reflexes and widespread respiratory wheezes.

Following the administration of $60 \%$ oxygen by

Correspondence: A.G.Fraser, M.B., M.R.C.P.

*Present address: Accident and Emergency Department, Royal Gwent Hospital, Newport, NP9 2UB, UK.

Dr Weston is Prophit-Rosser Fellow of the Royal College of Physicians of London.

Accepted: 18 February 1992 face-mask she recovered consciousness and complained of chest pain radiating to both elbows. An electrocardiograph demonstrated right bundle branch block and ST segment elevation in V2 to V6. She received glyceryl trinitrate and diamoro phine, and an infusion of streptokinase $(1.5 \mathrm{~m} \Phi$ over 60 minutes). During the infusion there was a episode of sustained ventricular tachycardia which resolved after lignocaine was given. Although the ST segment changes resolved rapidly there was evidence of a Q-wave myocardial infarction and the cardiac enzymes were elevated (peak creatine kinase (MB) $>155 \mathrm{ng} / \mathrm{ml}$ ). Her remaining inhospital course was further complicated by chest infection and she was discharged 15 days after admission.

On assessment 3 months later, a gated isotope study showed an ejection fraction of $54 \%$. She completed stage 4 of the standard Bruce protocol exercise test without evidence of exercise-induced arrhythmias or ischaemia. A left ventriculogram showed a small area of anterior akinesis (Figure 1). The coronary arteries appeared free of atheroma but there was a segment of myocardial bridging over the middle third of the left anterior descending coronary artery (Figure 2). By projecting the angiographic image onto a large screen, and using calipers to allow accurate measurement, there was shown to be a $36 \%$ reduction in coronary diameter (systolic frame compared to diastolic frame) at the site of the bridging.

\section{Discussion}

Up to $90 \%$ of deaths in victims of fire are related to smoke inhalation, rather than burns, ${ }^{3}$ and the 
a

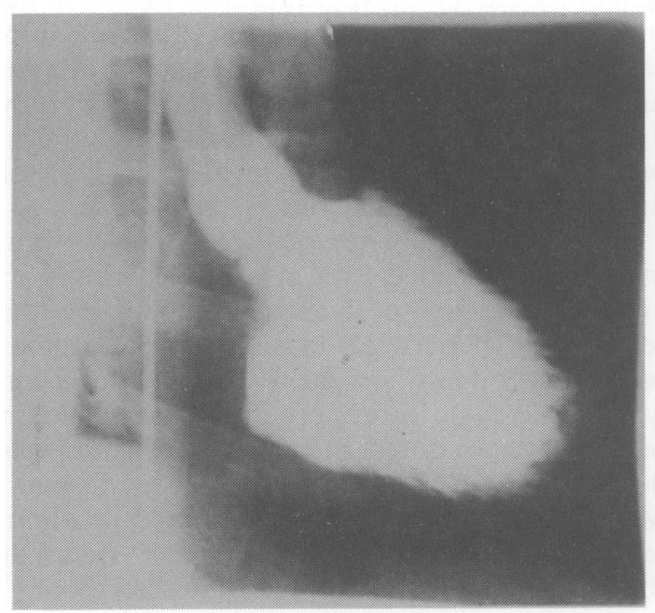

b

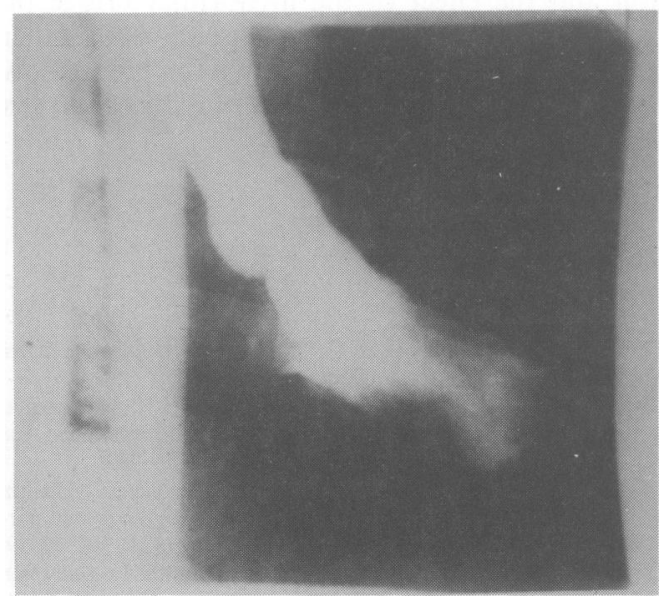

Figure 1 Left ventricular angiogram (right anterior oblique projection) demonstrating anteroapical akinesis: (a) diastole; (b) systole.

majority of these are attributable to carbon monoxide toxicity. ${ }^{4}$ This toxicity is mediated through tissue anoxia. The reduction in atmospheric oxygen concentration near a fire leads to decreased blood oxygenation ${ }^{4}$ and the formation of carboxyhaemoglobin, and carboxymyoglobin causing impaired oxygen delivery to the tissues. ${ }^{5}$ Furthermore, cytochrome oxidase activity is reduced by both hydrogen cyanide and carbon monoxide. This latter effect impairs the ability of the heart to recover from transient ischaemia. ${ }^{6}$

The histological findings in the heart after acute carbon monoxide poisoning are diffuse focal areas a

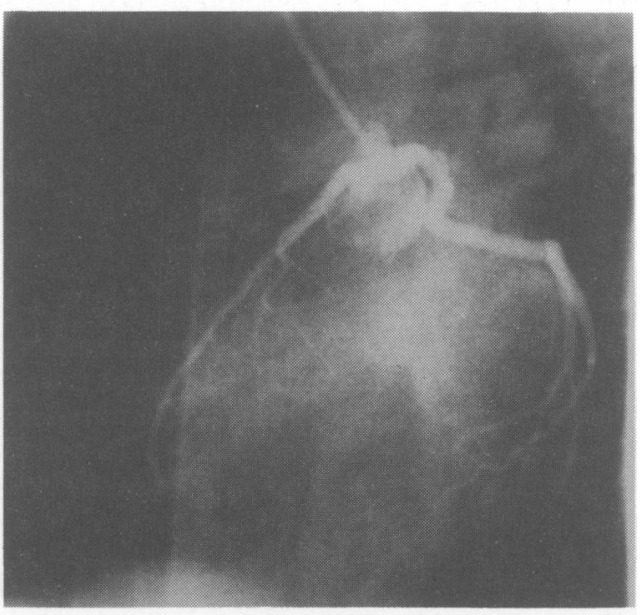

b

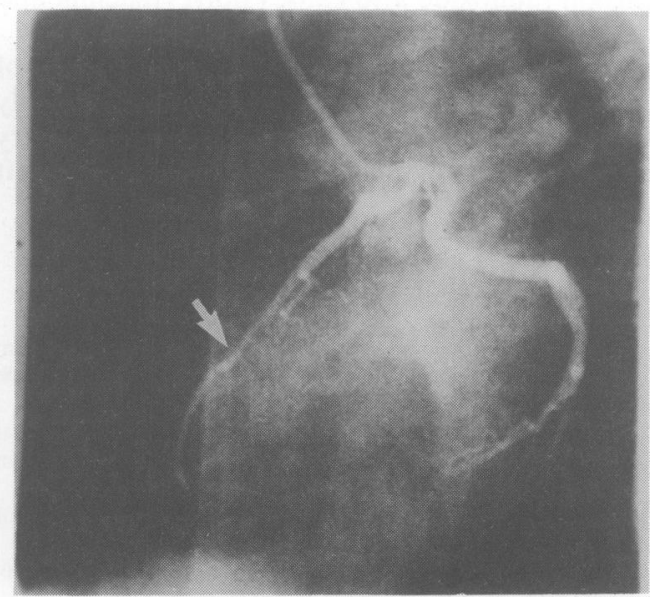

Figure 2 Left coronary angiogram (left anterior oblique projection) demonstrating myocardial bridging (arrowed) over the middle third of the left anterior descending artery: (a) diastole; (b) systole.

of necrosis, inflammatory cell infiltrates and punctate haemorrhages. ${ }^{7}$ These changes are most marked in the subendocardium of the left ventricle (which is at greatest risk of ischaemia) ${ }^{8}$ leading to reversible abnormalities of left ventricular wall motion without evidence of segmental infarction 9 and in the papillary muscles ${ }^{1}$ leading to mitral valve prolapse. ${ }^{9}$

Electrocardiographic changes due to this diffuse myocardial damage include sinus tachycardia and ST segment depression; ST elevation is rare. ${ }^{1,7,10}$ In case reports of acute mycardial infarction after carbon monoxide inhalation the victims have been 
presumed to have pre-existing coronary artery disease, though this has not always been proven angiographically. ${ }^{2,11}$

The young woman reported here suffered an acute Q-wave anterior myocardial infarction, rather than diffuse damage, after smoke inhalation, though there was no preceding history of chest pain or evidence of coronary artery disease. The possible causes of the infarction are coronary vasospasm, primary coronary thrombosis or some contribution from the documented myocardial bridging.

Although the early literature describes a state of 'acute arteriosclerosis' after severe carbon monoxide poisoning, with arterial spasm in extremities and brain, ${ }^{12}$ it has been shown in canine models that exposure to carbon monoxide results in coronary artery vasodilatation and increased myocardial blood flow. ${ }^{13}$

There is evidence of an increased thrombotic state consequent to acute carbon monoxide inhalation. Total plasma volume is reduced (and vascular permeability increased) after exposure to the gas. ${ }^{14}$ Carbon monoxide also causes polycythaemia and increased platelet aggregability. ${ }^{15,16}$

Myocardial bridging is reported in $0.5-5.0 \%$ of coronary angiograms, ${ }^{17-19}$ most commonly affecting the left anterior descending coronary artery and being most obvious in cases of left

\section{References}

1. Ehrich, W.E., Bellet, S. \& Lewey, F.H. Cardiac changes from carbon monoxide poisoning. Am J Med Sci 1944, 208: 511-523.

2. Scharf, S.M., Thomas, M.D. \& Sargent, R.K. Transmural myocardial infarction after exposure to carbon monoxide in coronary artery disease. $N$ Engl J Med 1974, 291: 85-86.

3. Birky, M.M. \& Clarke, F.B. Inhalation of toxic products of fires. Bull NY Acad Med 1981, 57: 997-1013.

4. Beritic, T. The challenge of fire effluents. Br Med J 1990, 300: 696-698.

5. Astrup, P. Some physiological and pathological effects of moderate carbon monoxide exposure. $\mathrm{Br} \mathrm{Med} J$ 1972, iv: 447-452.

6. Snow, T.R., Vanoli,E., De Ferrari, G., Stramba-Badiale, M. \& Dickey, D.T. Response of cytochrome a,a3 to carbon monoxide in canine hearts with prior infarcts. Life Sci 1988, 42: $927-931$.

7. Anderson, R.F., Allensworth, D.C. \& DeGroot, W.J. Myocardial toxicity from carbon monoxide poisoning. Ann Intern Med 1967, 67: 1172-1182.

8. Hoffman, J.I.E. Transmural myocardial perfusion. Prog Cardiovasc Dis 1987, 29: 429-464.

9. Corya, B.C., Black, M.J. \& McHenry, P.L. Echocardiographic findings after acute carbon monoxide poisoning. $\mathrm{Br}$ Heart J 1976, 38: 712-717.

10. Middleton, G.D., Ashby, D.W. \& Clark, F. Delayed and long-lasting electrocardiographic changes in carbon monoxide poisoning. Lancet 1961, i: 12-14.

11. Atkins, E.H. \& Baker, E.L. Exacerbation of coronary artery disease by occupational carbon monoxide exposure: a report of two fatalities and a review of the literature. Am J Ind Med 1985, 7: 73-79. ventricular hypertrophy and following administra- 3 tion of nitrates or inotropic agents. ${ }^{20}$ Its role in the $\stackrel{\varnothing}{\varrho}$ production of myocardial ischaemia is controver-. sial. It has been estimated that systolic arterial $\overrightarrow{\vec{c}}$ narrowing may reduce coronary blood flow by only $5-30 \%{ }^{20}$ A study of 21 patients with typical myocardial bridging demonstrated no evidence of myocardial ischaemia at rest or on exercise. ${ }^{21}$

However, there are reported cases of myocardial infarction associated with myocardial bridges ${ }^{22,23}$ o and of the relief of chest pain following the resection of periarterial muscle. ${ }^{24} \mathrm{~A}$ patient has been described in whom acute coronary occlusion was treated by intracoronary streptokinase. When patency was restored myocardial bridging was demonstrated at the site of the occlusion. ${ }^{23}$ Moreover, a patient has been reported in whom rapid atrial pacing resulted in coronary spasm at the site of a myocardial bridge, and distal to it. ${ }^{25}$

We believe that the pathophysiology of the acute myocardial infarction described above involved both the tissue hypoxia secondary to smoke inhalation and the effect of the myocardial bridge on coronary blood flow. What would be in other circumstances a minor reduction in blood flow became a crucial factor at a time of reduced oxygen delivery.

12. Glaister, J. \& Logan, D.D. Gas Poisoning in Mining and Other Industries. Livingstone, Edinburgh, 1914.

13. Adams, J.D., Erickson, H.H. \& Stone, H.L. Myocardial metabolism during exposure to carbon monoxide in the conscious dog. J Appl Physiol 1973, 34: 238-242.

14. Siggard-Anderson, J., Petersen, F.B. \& Hansen, T. Plasma volume and vascular permeability during hypoxia and carbon monoxide exposure. Scand J Clin Lab Invest 1968, 22: 39.

15. Hamilton, A. \& Hardy, H.L. Carbon monoxide. In: Industrial Toxicology, 3rd ed. Publishing Sciences Group, Massachusetts, 1974, pp. 246-247.

16. Aronow, W.S. The effect of carbon monoxide on cardiovascular disease. Prevent Med 1979, 8: 271-278.

17. Noble, J., Bourassa, M., Petitclerc, R. \& Dyrda,I. Myocardial bridging and milking effect of the left anterior descending coronary artery: Normal variant or obstruction. Am J Cardiol 1976, 37: 993-999.

18. Ishimori, T. Myocardial bridges: A new horizon in the evaluation of ischaemic heart disease. Cathet Cardiovasc Diagn 1980, 6: 355-357.

19. Kramer, J.R., Kitazume, H., Proudfit, W.L. \& Sones, F.M. Clinical significance of isolated coronary bridges: Benign and frequent condition involving the left anterior descending artery. Am Heart J 1982, 103: 283-288.

20. Angelini, P., Trivellato, M., Donis, J. \& Leachman, R.D. Myocardial bridges: a review. Prog Cardiovasc Dis 1983, 26: $75-88$.

21. Voss, H., Kupper, W., Hanrath, P., Mathey, D., Montz, R. \& Bucking, J. Clinical correlations, lactate extraction, coronary venous bloodflow and thallium-201 myocardial imaging in patients with isolated left anterior descending muscle bridges: Normal variant or obstruction. Z Kardiol 1980, 69: 347-352. 
22. Feldman, A.M. \& Baughman, K.L. Myocardial infarction associated with a myocardial bridge. Am Heart J 1986, 111: 784-787.

23. van Brussel, B.L., Tellingen, C. \& Ernst, S.M.P.G. Myocardial bridging: a cause of myocardial infarction. Int J Cardiol 1984, 6: 78-82.
24. Betriu, A., Tubau, J., Sanz, G., Magrina, J. \& NavarroLopez, F. Relief of angina by periarterial muscle resection of myocardial bridges. Am Heart J 1980, 100: 223-226.

25. Grover, M. \& Mancini, G.B.J. Myocardial bridge associated with pacing-induced coronary spasm. Am Heart J 1984, 108: $1540-1543$ 